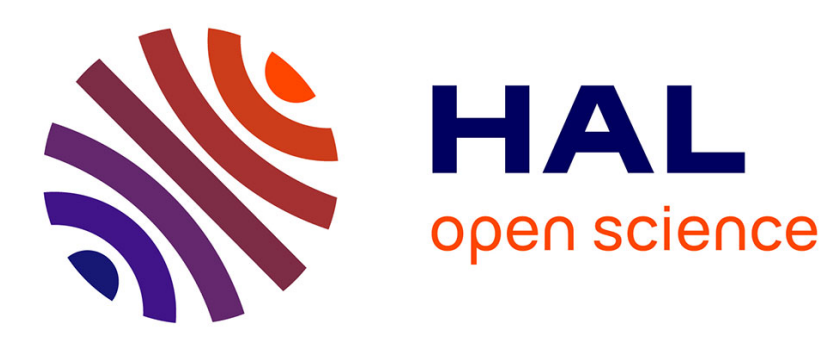

\title{
Towards efficient and reliable transportation systems
}

Neila Bhouri, Nadir Farhi

\section{To cite this version:}

Neila Bhouri, Nadir Farhi. Towards efficient and reliable transportation systems. Transportation research. Part C, Emerging technologies, 2014, 47 (1), pp 1-2. 10.1016/j.trc.2014.08.016 . hal01214481

\section{HAL Id: hal-01214481 \\ https://hal.science/hal-01214481}

Submitted on 12 Oct 2015

HAL is a multi-disciplinary open access archive for the deposit and dissemination of scientific research documents, whether they are published or not. The documents may come from teaching and research institutions in France or abroad, or from public or private research centers.
L'archive ouverte pluridisciplinaire HAL, est destinée au dépôt et à la diffusion de documents scientifiques de niveau recherche, publiés ou non, émanant des établissements d'enseignement et de recherche français ou étrangers, des laboratoires publics ou privés. 


\section{Neila Bhouri and Nadir Farhi}

\section{Université Paris-Est, IFSTTAR / COSYS / GRETTIA, France.}

\section{Towards efficient and reliable transportation systems}

This Special Issue contains articles selected from the 15th meeting of the Euro Working Group on Transportation (EWGT) held in Cité Descartes, Paris, in September 2012. EWGT is one of the 28 groups of EURO (Association of European Operational Research Societies). Our group, founded in Cetraro, Italy, in 1991, studies applications of operational research methods for transportation problems. The first EWGT meeting was held in 1992 in Landshut, Germany. EWGT meetings have since become conferences of international stature, attracting researchers from all over the world, although the majority come from Europe.

The EWGT 2012 meeting was organized with the special focus: "Energy efficiency in transportation and mobility systems". About 250 papers were submitted, from which about 170 were accepted and presented in Paris. They were classified into five streams as follows: A-Planning and economics, B-Transport and operations, C-Traffic analysis and management, D-Traffic simulation on networks, and EBehavior and eco-driving. Of the papers presented, 135 were selected and published in Procedia - Social and Behavioral Sciences, Volume 54, 2012. We chose six of the best papers for this Special Issue. The texts were substantially extended by their authors and reviewed according to the standards of the Transportation Research Part C. Six more papers from the EWGT 2012 meeting appear in the Special Issue of the European Journal of Transport and Infrastructure Research (EJTIR). ${ }^{2}$

The key problem in this Special Transportation Research Part C Issue was to establish directions and strategies in the conception and optimization of transportation systems, in order to increase their efficiency and meet new challenges. First of all, a transportation system must perform its main function efficiently and comfortably, and this consists of responding to displacement demands through appropriate transportation networks. The efficiency of these systems must be such that they can continue to operate in the face of high levels of traffic demand. The comfort deals in particular with the transport of people, allowing them to travel safely and comfortably in acceptable, reliable times. These issues are tackled in the paper by Leurent, Chandakas and Poulhès, on traffic assignment in transit networks; in the paper by Boujnah and Leurent on traffic assignment of parking and route choice; and in the one by Coulombel and de Palma on the social cost of travel time variability. The first authors propose a static macroscopic model of traffic assignment to a transit network, in which several capacity phenomena are captured. The model takes into account various capacity parameters, such as in-vehicle crowding, sitting and standing places (seat capacity), waiting time on platforms, vehicle dwell time at stations, run time of vehicles and passengers, service frequency, etc. A large-scale application to the whole transit network of the Grand Paris area (France) is presented. The article by Boujnah and Leurent presents a traffic assignment model of parking and route choice, in which travelers choose their routes according to the traffic costs associated with each route, and on the availability of parking (types of parking, fares, capacities, etc.). The model contains an example of planning, illustrating the effects of insufficient parking capacity on travel costs and network flows. The paper by Coulombel and de Palma examines the cost of variations in travel time for car users in peak rush hours, and presents a model for deriving the marginal social cost of such variations. Unlike models treating the value of variations in travel time, the above authors discuss feedback on variations in travel time on congestion profiles, and confirm results with data analysis from the Paris area.

A second important point is that a transportation system must be robust against disturbances, which are well-known to be complex and subject to several kinds of uncertainty. Transportation models must take into account all the sources of uncertainty, whereas system optimization must make its operation robust against various types of disturbances. In addition, degraded modes must either be taken into account in the transportation model or modeled and optimized separately. The article by D'Ariano, Samà and Pacciarelli, selected for this Special Issue, concerns aircraft traffic. The authors compare centralized and rolling horizon traffic control methods for air traffic monitoring and control in a busy terminal control area. In disturbed take-off and landing operations, the control problem minimizes propagation of delays, air-craft travel time, energy consumption, etc. Various hypothetical disturbance scenarios are simulated for Milan Malpensa, a real-world airport case-study, and the proposed timing and routing approaches are compared.

Third, the conception and planning of any transportation system is based on specific measurements and estimations (traffic flows, occupied spaces, transit zones, etc). The latter are essential in developing and validating any model. Real-time control of transportation systems also requires such measurements and estimations of transportation indicators. Therefore, the availability of transportation 
datasets is a key factor for any successful transportation study. When some traffic counts are not available, estimations from other traffic counts may be the only remedy for traffic experts and those who are interested in knowledge of traffic flows for site-specific studies, sometimes at particular periods of the year. The article by Rossi, Gastaldi and Gecchele presents an approach for estimating annual average daily traffic from limited data on a one-week seasonal traffic count of a road section. The approach combines fuzzy set theory and artificial neural networks. Tests were carried out with data from the Provence of Venice, Italy.

Both observation and control of a transportation system may be significantly improved by integrating new information and communication technologies. For example, traffic estimations (in terms of travel times, car densities, velocities, etc.) are being improved, thanks to the use of GPS, mobile apps, etc. In this direction, the article by Guido, Gallelli, Saccomanno, Vitale, Rogano and Festa presents results from several vehicle tracking tests and compares smart-phone speeds to benchmark values obtained from a high-frequency calibrated V-Box for three types of routes. The authors present a relation which provides speed adjustment factors for smart-phone probe estimates. Speed profiles measured by a stationary radar detector placed at a station along the SS106, in southern Italy, are compared with smart-phone speed profiles, in the two cases of using or not using speed adjustment as an uncertainty parameter.

We would like to thank all the EWGT authors and all the reviewers for their professional work, which allowed us to edit this Special Issue of Transportation Research Part C. Special thanks go to Prof. Markos Papageorgiou, former Editor-in-Chief of the journal, for inviting us as guest editors. Our thanks also go to his Successor, the late Matthew Karlaftis, and to the Journal Manager, Dipudass Dasan, for their support. 